\title{
Educação Ambiental e Questões Epistemológicas: algumas reflexões ${ }^{1}$
}

\author{
Paulo Ernesto Diaz Rocha ${ }^{2}$ \\ USP - Programa USP Recicla / Agência USP de Inovação
}

resumo: Para se entender a interação humano-meio na pós-modernidade, devemos desenvolver teorias relacionadas às noções de sistema, do corpo, das significações, buscando a verdade (ciência) $e$ o bem (filosofia), procurando investir numa energia moral. A Modernidade, símbolo do domínio da natureza por uma ciência matematizante que se pretende universal, sofre desconstrução por uma PósModernidade, mesmo que tal idéia se mantenha ainda fluídica, na intenção de se abarcar multiplicidade, imprevisibilidade, multidimensionalidade temporal, complexidade etc. Assim, indagamos: há no debate Modernidade X PósModernidade, se pertinente, uma unidade metodológica que daria conta da Educação Ambiental ou mesmo de uma Ciência Ambiental? Por ser multintertransdisciplinar e pelo fato de ocorrer divergências metodológicas nas ciências, seria possível apoiar uma multiplicidade, situando-a como abertura a uma nova visão de mundo que se pretende igualitária, justa, democrática? Perante os discursos epistemológicos: como nos posicionarmos para a recriação de valores ou propostas da Educação Ambiental em nossa realidade? Eis algumas das perguntas que este texto levanta, mas está longe de responder às mesmas.

palavras-chave: Educação ambiental, Epistemologia.

abstract: To understand the human-environment interaction in postmodernity, we must develop theories related to the notions of system, the body, the meanings, seeking the truth (science) and the good (philosophy), trying to invest in a moral energy. The Modernity, symbol of nature domination by a mathematical science that claims itself to be universal, suffers deconstruction by a Postmodernity, even if this idea still remains runny, so as to embrace diversity, unpredictability, multidimensional time, complexity etc. So, we ask: is there, in the Modernity X Postmodernity discuss, if appropriate, a methodological unity that would meet the requirements of Environmental Education or even of an Environmental Science? Considering it is

\footnotetext{
1 Parte deste artigo é oriunda de minha tese de doutorado "Interdisciplinaridade e Meio Ambiente em Cursos de Pós-Graduação no Brasil” (UFRRJ, 2001) e acessível no sítio da Rede Sul Brasileira de EA (http://www.reasul.org.br/mambo/index.php?option=com_ content\&task= view\&id=52\&Itemid=33).

2 Contato: pdiaz@usp.br Foram colaboradores destas idéias durante o evento os participantes do GDP "Educação Ambiental e Questões Epistemológicas", unidos após o evento pela lista de discussão GDP Episteme-EA (http://br.groups.yahoo.com/ group/GDPEpisteme-EA).
} 
multi-inter-transdisciplinary and that methodological differences do occur in science, could it support a multiplicity, placing it as an opening to a new vision of the world - equal, fair, democratic? Before the epistemological speeches: how to take a position for the recreation of values or proposes of Environmental Education in our reality? These are some of the questions raised in this text, but it is far from answering them.

keywords: Environmental education, Epistemology.

\section{Sobre Epistemologia}

A epistemologia pode ser considerada uma metaciência, pois tem a pretensão de reunir rigor e acaso, leis absolutistas da ciência clássica com mecânica relativista e filosofia. Sua importância aumenta com a crise de fundamentos tradicionais, proporcionando a possibilidade de juntar competência científica e reflexão filosófica. As fronteiras da especialização demonstram limites móveis no contato da teoria do conhecimento com outros meios de saber. A epistemologia estuda tanto o epistemológico quanto o ontológico, tanto o sujeito cognoscente quanto o objeto conhecido, não distinguindo alma e corpo. Bachelard (1971), Piaget (1980) e Blanché (1983), por exemplo, abordam o conhecimento a partir e através da história de sociedades e indivíduos, sem negar campos 'pré-científicos' da cognição. A epistemologia, por outro lado, aponta também para a ruptura das ciências com o conhecimento comum, vulgar, sendo esse afastamento da cultura geral demonstração de limites relativos ${ }^{3}$. Do mesmo modo, a reflexão epistemológica indica a incapacidade dos métodos e a necessidade de novos meios, sugerindo pluralidade e proliferação, cruzamentos e junções, enfim, o caráter pouco rígido e mutável de cada ciência, sem lugar exato e definitivo. O conhecimento homogêneo, organizado por uma 'razão universal' e estável, baseado na quantidade, pode ser conduzido, segundo esses autores, para um quadro geral maleável e aberto que possibilite comunicações e reorganizações. O desacordo entre teorias que buscam causas ou leis,

\footnotetext{
${ }^{3} \mathrm{O}$ limite do conhecimento científico, de acordo com Bachelard, não significa pensamento limitado, pois o espírito científico traça fronteiras e já as ultrapassa, uma vez que são zonas de pensamentos ativos, domínio de assimilação, paragem momentânea do pensamento.
} 
explicação ou preservação de fenômenos, parece sofrer atenuações quando se considera mecanismo $e$ energetismo (ou vitalismo), behaviorismo $e$ reflexividade, história dos acontecimentos $e$ a explicativa.

Portanto, a epistemologia sofre uma fértil indecisão entre filosofia e ciência, constituindo-se numa atitude reflexiva sobre o conhecimento (avaliação, racionalização e crítica), mas, buscando rigor, procura transferir a discussão filosófica para a objetividade científica. Entretanto, Bachelard lembra que a ciência propriamente dita tampouco é perfeitamente objetiva, uma vez que o cientista já se compromete com sua pesquisa: a escolha compreende caráter filosófico, sendo óbvio que de cada ato psicológico de conhecimento surjam perturbações ou inércias, obstáculos epistemológicos, preconceitos ou hábitos intelectuais. Segundo ele, o espírito científico se forma contra a natureza, pois combate o fato variado, e, deformando-a, exige purificar e ordenar fenômenos, resistindo: uma ciência imóvel e isolada, desligada das observações iniciais, se mostra como antiphysist.

Piaget, por outro lado, defende uma lógica natural ou das significações, pois significados implicam pressupostos mentais, novas idéias, conceitos, juízos, dialética - implicações entre ação e significado. Para Blanché, uma ciência inteiramente positivista, sem controvérsias, é apenas um ideal, já que há um "empate" no confronto entre idealistas $e$ empiristas, logicistas $e$ intuicionistas: ou seja, uma soma entre o caráter lógico ou analítico $e$ o intuitivo ou sintético.

Bachelard crê que a cultura científica deve começar por uma catarse intelectual e afetiva, propor um estado de mobilização permanente, substituir saber fechado pelo dinâmico e dialetizar variáveis experimentais: dar à razão razões para evoluir. A crise do determinismo no saber científico, que legitima a lógica do desempenho, da relação input/output colocada pela filosofia positivista da eficiência, é questionada por Lyotard (1986). Ele percebe a necessidade de expansão da ciência pelo trabalho de argumentação, inventando o contra-exemplo, pesquisando paradoxos para

4 Tudo o que nasce brota, surge, vem a ser; também luz (mundo natural). Significado oposto ao de nomos, nomoi, de onde vem normas (mundo humano). O termo physis depois foi consagrado em latim como natura, de provável origem nascor, nascere. Physis + logos $=$ fisiologia: originariamente, ciência da natureza dos seres ou do meio e, mais tarde, Física (BARBOSA, 1995). 
relegitimá-los. A regularidade e a previsibilidade perseguidas pela ciência clássica e o cálculo de todas as variáveis se mostram impossíveis, pois são ao mesmo tempo dependentes e independentes. A própria ciência, através do progresso da Física Quântica e da Microfísica, é desconstruída, confirmando seu paradoxo quando questiona enunciados através do discurso, ao mesmo tempo em que percebe limites e avanços do próprio saber (LYOTARD, 1986, p. 104).

Assim, a epistemologia contribui para o debate frente à transformação do paradigma científico e à complexidade de problemáticas tais como a social e a ambiental. Nela, fica clara a questão de interdependência do sujeito e do objeto, do meio e do ser, o que resvala na complexidade epistemológica discutida pelos autores citados. A fusão ato $e$ ser, onda $e$ corpúsculo, objeto $e$ movimento; 'o que é' $e$ 'o que vem a ser' da mecânica relativista passa a considerar um corpo como centro de irradiação, pretexto de pensamento; relação e não apenas objeto concreto discernível por leis absolutas. A filosofia tem então a incumbência de apresentar o drama cotidiano, a rivalidade e a cooperação entre esforço teórico $e$ investigação experimental e o eterno conflito de métodos.

Desse modo, o entendimento de que a questão ambiental constitui um conjunto multifacetado de implicações sociais, políticas e econômicas exigiu a compreensão dos valores que orientam a relação homem/natureza. Isso se traduz numa aproximação conceitual entre as Ciências Humanas e Naturais como resposta epistemológica ao paradigma dualista estabelecido pela racionalidade moderna entre esses campos do conhecimento.

Em síntese, a compreensão de que problemas ambientais implicam e são implicados por valores e concepções comuns na sociedade disseminou a idéia de que é o modo moderno de organização do pensamento, da produção e dos estilos de vida que está em crise. Daí decorre um pessimismo sobre as possibilidades modernas e uma maior percepção das contradições inerentes ao avanço da ciência, da técnica, da tecnologia, do desenvolvimento industrial, da produção e da sociedade do consumo. Embora vistos como decisivos à consolidação da vida moderna, gerando conforto e o domínio sobre a natureza, seus benefícios mostramse cada vez mais restritos e suas conseqüências, cada vez mais ameaçadoras (GIDDENS, 1991). 


\section{Sobre Paradigmas}

$\mathrm{Na}$ área das Ciências Sociais, confirmando os apontamentos de Goldmann (1967), Bourdieu (1989) e Lövy (1996), busca-se uma epistemologia sociológica como a cogitada por Alexander (1987): uma 'teoria geral' que supere a unilateralidade de trabalhos empíricos e das micro e macroteorizações, provocando grandes contradições internas. Assim como apontado por Kuhn (1994), argumentos não empíricos e filosóficos influenciam também as áreas exatas e, portanto, a Ciência Social não pode ser vista como Ciência Natural interpretativa.

Porém, para Alexander, a Sociologia é marcada pelo dissenso, uma rotina de crises de paradigma, abordando questões supra-empíricas e promovendo debates filosóficos. As inerentes desavenças cognitivas e valorativas da relação observador e observado se mostram como um conflito saudável, buscando combinar compromissos racionais com supraempíricos, uma teoria multivalente persuasiva ou metateoria. Há, por conseguinte, uma interpretação moderada entre ambas as tendências: uma teoria geral, sintética, objetiva e normativa junto a uma teoria da cultura, ponte que evita degenerar em idealismo, arbitrariedade e irracionalismo, preservando criatividade e desenvolvendo uma teoria multidimensional. Para esse autor, o esforço em sintetizar ação $e$ estrutura, cultura $e$ força material se faz pela necessidade existencial de reduzir a complexidade, aproximando indivíduo e ambiente e suas reflexividades.

Lyotard (1986), comentando sobre o desaparecimento do paradigma do conhecimento e da previsão, corrobora a idéia de descontinuidades - o inesperado de catástrofes que interferem na aparente e pretensa homogeneidade do observável. A imprevisibilidade do sistema confirma seu aspecto instável, embora um caráter determinado possa existir momentaneamente, mas apenas relativo ao local e não tendendo à estabilização. Assim, ele concorda com a inevitabilidade do conflito, pois são mínimas as chances de controle total, já que revelam apenas "ilhas de determinismo". A ciência pós-moderna torna a teoria de sua própria evolução descontínua, catastrófica, não retificável, paradoxal, fazendo mudar o sentido, já que produz o desconhecido (LYOTARD, 1986, p. 107). Ele crê 
em uma ciência como campo aberto, pragmática e centrada nos enunciados denotativos ou de conhecimento, não prescritivos ou de ação.

Kuhn (1994, p. 213), do mesmo modo, constrói seu pensamento a partir da crítica da ciência lógico-positivista e seu processo cumulativo e contínuo, já que o princípio organizador sofre influências psicológicas e sociológicas que conformam paradigmas. Com base na pesquisa em sociologia da comunidade científica e na história das ciências, ele indicou a alternância de períodos normais (monísticos, uniparadigmáticos) e revolucionários (pluralísticos, pluriparadigmáticos). A convivência com diferentes cientistas fez com que abordasse os desacordos dos métodos, questionando se as Ciências Naturais apresentam respostas mais firmes ou permanentes do que as Sociais. Desvelou então que uma metafísica criadora ou assimilações inovadoras promovem a emergência de anomalias que trazem problematização ou contradição que permanecem ou não, uma vez que violações de expectativas atraem a comunidade, enquanto o fracasso repetido pode induzir à crise. Assim, para ele, paradigmas são realizações científicas universalmente reconhecidas que fornecem problemas e soluções modelares. Desse modo, as teorias sofrem rupturas e processos de negociação na fase revolucionária, quando entram em jogo relações de poder, autoridade e dependência - a base sociológica de sua teoria.

Morin (1996) adota a definição de paradigma além da lingüística, vendo o termo como um tipo de relação dominadora forte de conjunção ou não de conceitos-chave, cuja concepção cartesiana ocidental impede a unitas multiplex, a comunicabilidade entre sujeito e objeto, impondo um divórcio trágico entre filosofia e ciência. Luizari e Cavalari (2003, p. 8) evidenciam o ponto de vista desse autor sobre o paradigma que reconhece e comanda rupturas entre sujeito e objeto, alma e corpo, espírito e matéria, qualidade e quantidade, finalidade e causalidade, sentimento e razão, liberdade e determinismo, existência e essência.

Criticando a divisão do conhecimento em disciplinas não comunicantes, Morin se alinha a Bateson (1986) e Maturana e Varela (1980) quando distingue três níveis não redutíveis, mas articulados da cognição: organizacional, biológico e psíquico, sendo a condição bioantropológica do conhecimento de todo ser vivo como autoecorganizador, ao mesmo tempo aberto e fechado. Há, portanto, um 
equilíbrio dinâmico entre complementaridade e antagonismo, o ingrediente abstrato (da esfera simbólico-mítico-mágica) tão necessário quanto o material (da esfera racional-empírica) que sustentam a identidade comum. Para Morin, esse exemplo tem relação com ideologias, ao mesmo tempo imaginativas e reais, lógicas $e$ abstratas, mas que atuam objetivamente, advogando então uma nova ciência do espírito, dos mitos e das idéias. Esta traria a soma da lógica e das incertezas e contradições, a interação ondacorpúsculo (energia-matéria) e o continuum filogenético.

Advogando a possibilidade de um "paradigma de produtividade ecotecnológica", Leff (1994, p. 103) confere às contradições expressas no confronto entre interesses sociais, estruturas institucionais, paradigmas e processos de legitimação o fato irredutível da lógica única. Entretanto, essa postura exige consciência ambiental, reforma democrática e participativa do Estado, reorganização da administração pública e reelaboração interdisciplinar do saber, através da dialética teórica emersa da consciência crítica sobre o conflito de interesses sociais particulares. Embora ele seja contra a racionalidade econômica de forças cegas do mercado, procura aceitar o caráter relativo e oposto de ambas as racionalidades e percebe quatro tipos de racionalidade ambiental: substantiva (valores), teórica (conceitos, suporte, produção), técnica ou instrumental (vínculo social e material) e cultural (significações, identidade e integridade), demonstrando a diversidade e a impossibilidade de uma lógica ambiental geral. Apesar do confronto entre as lógicas opostas tecnológica e ambiental, Leff acredita na utopia de um projeto social novo no campo da sociologia do conhecimento, com o questionamento generalizado à racionalidade dominante e ao modelo de cientificidade, compartimentalizado e alienado. A verdadeira revolução ideológica e cultural, para ele, pode abalar os saberes científicos estabelecidos caso se apóie em práticas discursivas e na práxis crítica e propositiva.

\section{Concretamente}

Um grande e moderno autor que trata muito bem desses assuntos numa perspectiva sociológica e efetivamente atual é Wallerstein (1997). Em seu texto "Incerteza e Criatividade", comenta que o mundo não progrediu moralmente para uma 'racionalidade substantiva' (citando Max Weber), 
com valores e fins racionais, coletiva e inteligentemente. Para ele, acreditar em certezas, premissa da modernidade, não mais se mantém. A ciência moderna, cartesiano-newtoniana, se baseou na certeza das certezas, ou seja, leis universais governando todo fenômeno natural, cuja descoberta iria predizer o futuro e revelar o passado. Assim, houve a secularização do pensamento cristão e idéias como as de Prigogine sobre a flecha do tempo que aponta para a irreversibilidade dos fenômenos, indicando o nãodeterminismo linear almejado. Segundo esse pensador, se tudo está incerto, o futuro está aberto para a criatividade, não apenas humana, mas de toda a natureza, até mesmo para a possibilidade de um mundo melhor. Porém, esse passo adiante só será dado se investirmos nossas energias morais nesse sentido, se estivermos lutando por isso, por um mundo igualitário e democrático. Algo a ver com a EA brasileira?!

Em seu outro texto "The Structures of Knowledge, or How Many Ways May We Know?” (As estruturas do conhecimento ou De quantas maneiras nós podemos saber?), Wallerstein demonstra a rejeição da Teologia pela Filosofia, uma vez que os humanos substituíram deus como fonte de conhecimento. Do mesmo modo, a Filosofia passou também a ser contraditória à Ciência, como se fossem duas culturas totalmente diferentes. Porém, essa é apenas uma construção social recente, baseada na empiria cujo racionalismo rejeitou a especulação dedutiva. Ele denuncia que a Ciência não é democrática, pois é tratada apenas por especialistas em suas comunidades que distinguem radicalmente Bem e Beleza de Verdade, divórcio que vem sofrendo aproximações apenas clandestinas e por isso não progride.

O mesmo autor cita, porém, que estudos culturais e da complexidade atacam tais problemas e abrem o campo do conhecimento: não resultando num universalismo, mas sim em racionalidades várias, na aceitação da entropia, na percepção de uma natureza não passiva e também auto-organizadora, somada à física quântica, que colocou a questão do futuro indeterminado e do fluxo contínuo, ininterrupto e sem 'ctrl z' do tempo... Desse modo, ele aponta novamente para a necessidade de ênfase na criatividade humana e da natureza, para a necessária visão integrada, para o movimento em direção às Ciências Sociais, para a reintegração do conhecimento do Bom e do Verdadeiro e para a reconstrução das instituições. Alerta também para o perigo daqueles que defendem a 
distribuição desigual de recursos e do poder, pois somente com a proposição de uma nova ordem social [um novo mundo possível] se fará uma real fortuna. E fecha dizendo: we can only have fortuna if we seize it.

\section{Considerações finais}

Apodero-me das idéias do filósofo Marcondes (1997) com o intuito de fazer um breve resumo sobre o acima colocado, tentando delinear algo sobre a chamada pós-modernidade ou filosofia contemporânea. Esta seria uma não corrente ou doutrina, unidade teórica, metodológica ou sistemática, mas ponto comum de inúmeros autores: a busca por novos rumos para o pensamento, concebendo filosofia mais próxima da arte do que da ciência, não se pretendendo um saber ou ponto de vista privilegiado, mas prática discursiva, reflexão, entendimento da época e experiências para dar conta das transformações, especificidades e complexidades.

Dessa forma, reunindo apontamentos de reflexões coletivas do GDP e reaproximando-se da questão ambiental, será urgente que a Educação Ambiental crítica, filosófica, política e radical se espraie para entender a transformação do pensamento humano em relação ao meio onde vivemos neste período ao mesmo tempo de síntese e transição. Implica a discussão sobre métodos, sobre a Educação Ambiental como ciência, com princípios suportados por paradigmas atuais, apoiada numa ética concreta e cotidiana, que apontem objetivos e missão, utópicos $e$ possíveis...

Pensamos que, longe de uma resposta fácil e palatável, seria possível tentá-la a partir de uma visão que proporcione uma ação cotidiana (profissional, social, familiar) que promova desejos, criatividade $e$ arte, protagonismo e transgressão. Algo por aí! Ou não...

\section{Referências}

ALEXANDER, Jeffrey C. O novo movimento teórico. Revista Brasileira de Ciências Sociais, São Paulo, v. 2, n. 4, p. 5-42, jun. 1987.

BACHELARD, Gaston. A Epistemologia. Lisboa: Edições 70, 1971. 
BARBOSA, Wilmar do V. Sobre a Idéia da Natureza. Rio de Janeiro: ISER, 1995. p. 25. Apostila do Curso Teoria e Práxis do Meio Ambiente.

BATESON, Gregory. Mente e Natureza: a unidade necessária. Trad. de Claudia Gerpe. Rio de Janeiro: Francisco Alves, 1986.

BLANCHÉ, Robert. A epistemologia. Trad. de Natália Couto. Lisboa: Presença, 1983.

BOURDIEU, Pierre. O Poder Simbólico. Trad. de Fernando Tomaz. Lisboa. Rio de Janeiro: DIFEL; Bertrand Brasil, 1989.

CAMPBELL, Colin. A orientalização do ocidente: reflexões sobre uma nova teodicéia para um novo milênio. Religião \& Sociedade, Rio de Janeiro, v. 18, n. 1, p. 5-22, 1997.

GIDDENS, Anthony. As Conseqüências da Modernidade. Trad. de Raul Fiker. São Paulo: Editora da UNESP, 1991.

GOLDMANN, Lucien. A origem da Dialética: a comunidade humana e o universo em Kant. Trad. de Haroldo Santiago. Rio de Janeiro: Paz e Terra, 1967.

KRUS, D. J.; BLACKMAN, H. S. Contributions to psychohistory: East-West dimensions of ideology measured by transtemporal cognitive matching. Psychological Reports, Missoula, v. 47, p. 947-55, 1980.

KUHN, Thomas. A estrutura das revoluções cientificas. Trad. de Beatriz Vianna Boeira e Nelson Boeira. São Paulo: Perspectiva, 1994.

LEFF, Enrique. Sociologia e ambiente: sobre o conceito de racionalidade ambiental e as transformações do conhecimento. In: VIEIRA, Paulo Freire; MAIMON, Dália (Org.). As Ciências Sociais e a questão ambiental: rumo à interdisciplinaridade. Rio de Janeiro: APED; Belém, PA: NAEA, p. 95-130, 1994.

LIMA, Lauro de Oliveira. A escola secundária moderna. Petrópolis: Vozes, 1973.

LÖVY, Michael. Ideologias e Ciência Social: elementos para uma análise marxista. 11. ed. São Paulo: PUC; Cortez, 1996.

LUIZARI, Rosa Acassia; CAVALARI, Rosa Maria F. A contribuição do pensamento de Edgar Morin para a educação ambiental. Educação: teoria e prática, Rio Claro, v. 11, n. 20/21, p. 7-13, jan./dez. 2003.

LYOTARD, Jean-François. O Pós-Moderno. 2. ed. Rio de Janeiro: José Olympio, 1986.

MARCONDES, Danilo. Iniciação à História da Filosofia. Rio de Janeiro: Zahar, 1997. 298 p.

MATURANA, Humberto R.; VARELA, Francisco J. Autopoiesis and cognition: The realization of living. Boston: Kluwer Academic Publishers, 1980. (Boston Studies in the Philosophy of Science, v. 423).

MORIN, Edgar. Problemas de uma epistemologia complexa. In: O problema epistemológico da complexidade. Lisboa: Publicações Europa-América, 1996. p. 13-34. (Biblioteca Universitária, 38)

PIAGET, Jean et al. Construción y validación de las teorias cientificas: contribuición de la epistemología genética. Genebra: PAIDOS, 1980.

SANTOS FILHO, José Camilo dos. Pesquisa quantitativa versus pesquisa qualitativa: o desafio paradigmático. In: SANTOS FILHO, José Camilo dos; GAMBOA, Silvio Sánchez (Org.). Pesquisa educacional: quantidade-qualidade. São Paulo: Cortez, 1997. p.13-59. 
SANTOS FILHO, José Camilo dos; GAMBOA, Silvio Sánchez (Org.). Pesquisa educacional: quantidade-qualidade. São Paulo: Cortez, 1997.

WALLERSTEIN, Immanuel. The Structures of Knowledge, or How Many Ways May We Know? In: Which Sciences for Tomorrow? Dialogue on the Gulbenkian Report, Stanford University, June 2-3, 1996. Disponível em: <http://www.binghamton.edu/fbc/iwstanfo.htm>. Acesso em: dia mês abreviado ano.

Uncertainty and Creativity. In: Forum 2000: Concerns and Hopes on the Threshold of the New Millennium, Prague, Sept. 3-6, 1997. Disponível em: http://www.binghamton.edu/ fbc/iwuncer.htm. Acesso em: 05 jun. 2008.

\section{Anexos}

\section{Exemplos de Divisões Paradigmáticas}

Procurando discernir as diversas interpretações da idéia de paradigma, no esquema abaixo distingo três teorias do conhecimento que consubstanciam os paradigmas da relação humana com o meio, segundo
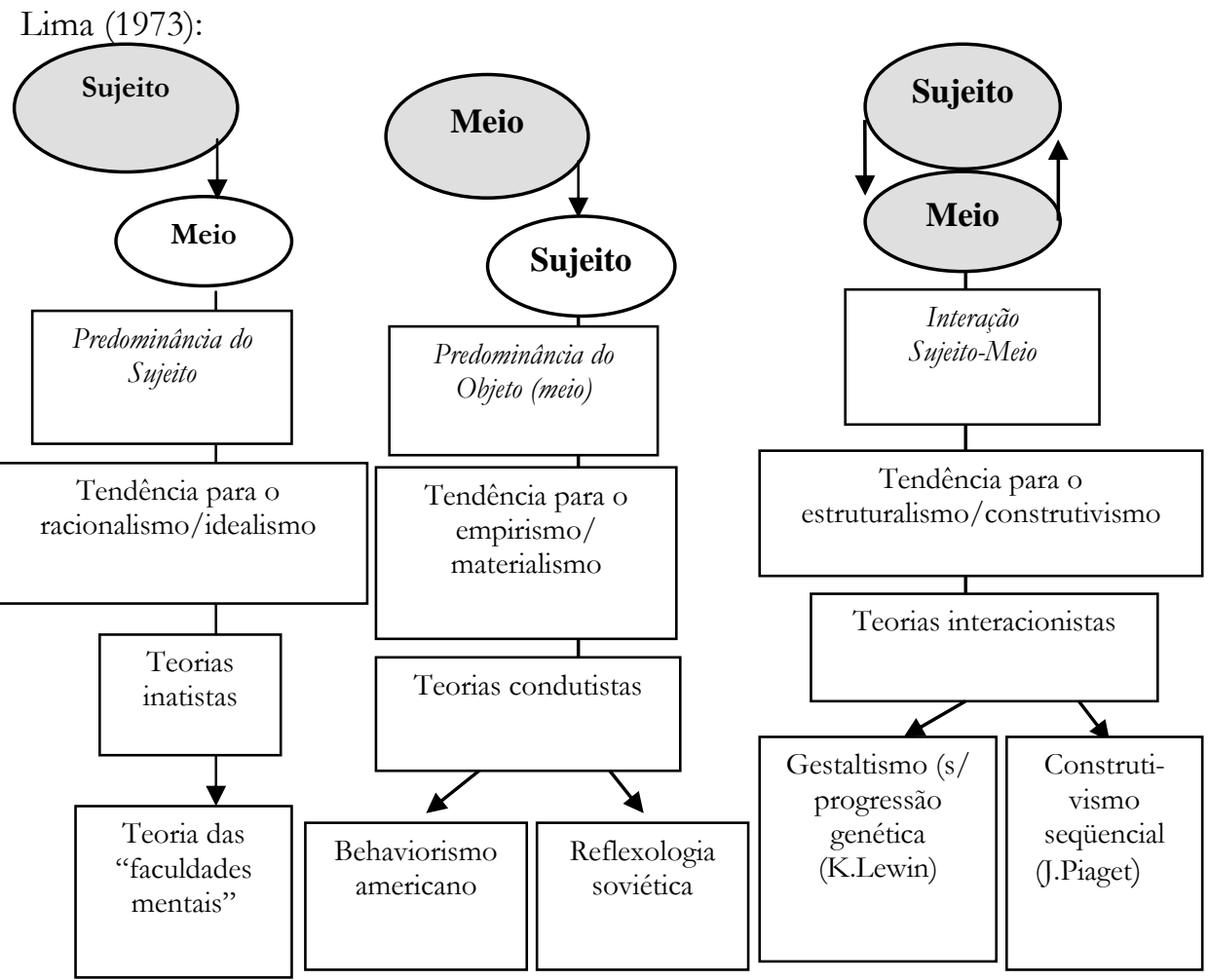
Diversos são os autores que apresentam divisões de paradigmas distintos, inclusive percebendo ou tentando defini-los de modo particular. Gilgen e Cho (1979 apud CAMPBELL, 1997), numa perspectiva mais antropológica, descreve a qualificação dos paradigmas ocidentais e orientais, apresentando a seguinte tabela, na qual coloca um suposto paradigma cartesiano oposto a um paradigma da complexidade:

\begin{tabular}{|l|l|}
\hline \multicolumn{1}{|c|}{ DUALISMO OCIDENTAL } & \multicolumn{1}{c|}{ MONISMO ORIENTAL } \\
\hline $\begin{array}{l}\text { O ser humano tem características que o } \\
\text { separam da natureza. }\end{array}$ & O ser humano e a natureza são um. \\
\hline $\begin{array}{l}\text { O ser humano é dividido em corpo, } \\
\text { mente e espírito. }\end{array}$ & Mente, corpo e espírito são um. \\
\hline $\begin{array}{l}\text { O ser humano deve rotular, categorizar, } \\
\text { manipular, controlar e consumir as coisas } \\
\text { do mundo da natureza para garantir sua } \\
\text { sobrevivência. }\end{array}$ & $\begin{array}{l}\text { O ser humano deve reconhecer sua } \\
\text { mentale com a natureza, o espiritual e o }\end{array}$ \\
\hline $\begin{array}{l}\text { O ser humano deve enfatizar o } \\
\text { pensamento racional e a abordagem } \\
\text { analítica para solucionar problemas e } \\
\text { angústias. }\end{array}$ & $\begin{array}{l}\text { Por causa de sua unidade com toda a a ser humano deve sentir-se } \\
\text { 'exian qualquer lugar e com } \\
\text { A ciência e a tecnologia têm-nos dado pessoa. }\end{array}$ \\
$\begin{array}{l}\text { uma vida boa e são nossa principal } \\
\text { esperança num futuro ainda melhor. }\end{array}$ & $\begin{array}{l}\text { A ciência e a tecnologia criam, na } \\
\text { melhor das hipóteses, uma ilusão de } \\
\text { progresso. }\end{array}$ \\
\hline
\end{tabular}

Segundo Krus e Blackman (1980), complementando a distinção acima, as principais características desses dois paradigmas são:

@ OCIDENTE: Análise, Generalização, Diferenciação, Indução, Objetivo, Intelectual, Razão, Ciência, Impessoal, Legal, Assertivo, Poder, Ordem, Racional e Crítico

@ ORIENTE: Síntese, Totalidade, Integração, Dedução, Subjetivo, Dogmático, Intuição, Anticiência, Pessoal, Moral, Não-discurso, Associativo, Exxtase, Irracional e Imaginativo. 
Já Santos Filho (1997) reuniu diferentes concepções e distinções de 'paradigma' a partir dos mais diversos autores. Embora haja certa afinidade entre eles, percebe-se a dificuldade em se sistematizar tais correntes epistemológicas distintas:

œ HABERMAS: 1 - Empírico-analítico (mundo físico), 2 Histórico-hermenêutico (eventos históricos) e 3 - Crítico (expor condições de opressão e dominação)

@ HOSHMAND: 1 - Naturalístico-etnográfico, 2 Fenomenológico-hermenêutico e 3 - Cibernético

@ T. HUSÉN: 1 - Científico (neopositivista), 2 - Idealista (Dilthey) e 3 - Humanista, que se desdobra em A - Fenomenológico e B Crítico (neomarxista)

@ SOLTIS (na área de educação): 1 - Empírico, 2 - Interpretativo, 3 - Crítico e 4 - Normativo

œ POPKEWITZ (também na área de educação): 1 - Empírico analítico e 2 - Ciência simbólica

@ BERSTEIN: 1 - Empírico, 2 - Fenomenológico e 3 - Crítico.

Quanto à relação entre esses diversos pensamentos científicos, Santos Filho e Gamboa (1997) explicitam algumas possíveis correlações entre paradigmas, distinguindo a visão do mundo ou premissas subjacentes, relação sujeito-objeto, relação fatos-valores, objetivo da pesquisa, abordagem, foco, método, papel da pesquisa e principais critérios da pesquisa. $\mathrm{Na}$ tabela abaixo, coloco as principais características de três diferentes teses: 1) $\mathrm{Da}$ diversidade incompatível, 2) $\mathrm{Da}$ diversidade compatível ou complementar e 3) Da unidade ou integração, oriundas de filósofos de inúmeras vertentes, segundo os atores citados.

Relação entre Tese da Diversidade Incompatível (Kerlinger, Smith, Lincoln \& paradigmas Guba e Smith \& Heshusius)

Visão do

mundo ou

premissas subjacentes
Quantitativa

Positivista-realista; realidade objetiva; homem suj. reator; busca verdade absoluta propondo modelos estáticos.

\section{Interpretativa}

Fenomenológico; realidade socialmente construída; homem sujeito-ator; busca verdade relativa aceitando teoria do conflito. 


\begin{tabular}{|c|c|c|}
\hline $\begin{array}{l}\text { Relação } \\
\text { sujeito-objeto }\end{array}$ & $\begin{array}{l}\text { Independente, externalista; } \\
\text { linguagem neutra, científica. } \\
\text { Verdade estabelecida via } \\
\text { experimentação empírica. }\end{array}$ & $\begin{array}{l}\text { Não dualista; realidade criada ou } \\
\text { moldada; linguagem real. Verdade } \\
\text { historicamente condicionada. }\end{array}$ \\
\hline $\begin{array}{l}\text { Relação fatos - } \\
\text { valores }\end{array}$ & $\begin{array}{l}\text { Fatos independentes do } \\
\text { sujeito; conhecimento } \\
\text { replicável. }\end{array}$ & $\begin{array}{l}\text { Atenção para o sujeito que baseia } \\
\text { valores. Objetividade a partir de acordo } \\
\text { social; através de justificação e diálogo. } \\
\text { Atores morais com valores positivos. }\end{array}$ \\
\hline $\begin{array}{l}\text { Objetivo da } \\
\text { pesquisa }\end{array}$ & $\begin{array}{l}\text { Predição, testagem de } \\
\text { hipóteses e generalização. } \\
\text { Explanação indutivo- } \\
\text { estatística de natureza } \\
\text { probabilística. Busca-se } \\
\text { regularidade. }\end{array}$ & $\begin{array}{l}\text { Busca compreensão, interpretação e } \\
\text { especificação em dois níveis: } \\
\text { direta/imediata e profunda do } \\
\text { significado-contexto. Interpretação do } \\
\text { movimento, s/ ponto absoluto. }\end{array}$ \\
\hline Abordagem & $\begin{array}{l}\text { Design experimental p/ } \\
\text { reduzir erro. }\end{array}$ & Hermenêutica/etnográfica. \\
\hline Foco & $\begin{array}{l}\text { Traços individuais, relações } \\
\text { causais, o 'porquê'. }\end{array}$ & $\begin{array}{l}\text { Experiência individual, senso comum, } \\
\text { processo de construção de significado, o } \\
\text { 'como'. }\end{array}$ \\
\hline Método & $\begin{array}{l}\text { Dedutivo (da teoria p/ os } \\
\text { dados), definições } \\
\text { predeterminadas, } \\
\text { racionalista, precessão por } \\
\text { medida e estatística, medida } \\
\text { de variáveis, grande } \\
\text { amostra. }\end{array}$ & $\begin{array}{l}\text { Indutivo (dos dados p/ a teoria), } \\
\text { definições do processo, intuição e } \\
\text { criatividade, explica via propriedades e } \\
\text { relações, síntese holística e análise } \\
\text { comparativa, pequena amostra } \\
\text { selecionada. }\end{array}$ \\
\hline $\begin{array}{l}\text { Papel da } \\
\text { pesquisa }\end{array}$ & $\begin{array}{l}\text { Distancia-se } \mathrm{p} / \text { evitar } \\
\text { vieses. }\end{array}$ & Imerge-se no fenômeno de interesse. \\
\hline $\begin{array}{l}\text { Principais } \\
\text { critérios }\end{array}$ & Fidedignidade. & Validade. \\
\hline
\end{tabular}




$\begin{array}{ll}\begin{array}{ll}\text { Relação entre } \\ \text { paradigmas }\end{array} & \begin{array}{l}\text { Tese da Diversidade Compatível } \\ \text { ou Complementar Cook \& } \\ \text { Campbell, Goergen, Soltis, Shulman, }\end{array} \\ & \begin{array}{l}\text { Keeves, Firestone, Cambi, Husén e } \\ \text { Gage. }\end{array} \\ \text { Visão do mundo } & \text { São contra a corrupção pela visão } \\ \text { ou premissas } & \text { paradigmática única. Não há um } \\ \text { subjacentes } & \text { antagonismo necessário entre os } \\ & \text { objetivistas, os interpretativistas e os } \\ & \text { teóricos críticos. } \\ \text { Relação sujeito- } & \text { Programas de pesquisa se preocupam } \\ \text { objeto } & \text { com problemas e tópicos diferentes, } \\ & \text { mas importantes. }\end{array}$

$\begin{array}{ll}\text { Relação fatos - } & \text { Uso do pluralismo epistemológico p/ } \\ \text { valores } & \begin{array}{l}\text { a complexidade dos problemas } \\ \text { educacionais. }\end{array}\end{array}$

Objetivo da pesquisa

Abordagem

Foco

Método
Abordagens mais holísticas são mais capazes $\mathrm{p} /$ abarcar maior complexidade.

Uso das abordagens quantitativa $e$ qualitativa $\mathrm{p} /$ maior predição.

Alguns não subscrevem a doutrina da incomensurabilidade dos paradigmas (Kuhn). Alguns minimizam diferenças epistem.

Tendência a 'desespistemologizar' o debate ou a ignorar diferenças paradigmáticas.

\section{Tese da Unidade ou}

Integração: filósofos pós-

positivistas e teóricos críticos

c/o Walker \& Evers e Howe.

Contrários à tese da existência de paradigmas, defendem epistemologia da coerência ou 'coerentismo' ou 'holismo epistemológico’.

Não há como dividir o domínio do conhecimento em formas de conhecimento radicalmente distintas. Contradição fictícia, simplista e artificial.

Não-distinção entre fatos e valores; quantidade e qualidade. O conhecimento está baseado em observações e crenças carregadas de teoria - Kuhn.

A teoria precede todo conhecimento ou aprendizagem. Os julgamentos de valor não podem ser excluídos da condução da pesquisa.

Dados quantitativos 'pressupõem' os qualitativos. Pesquisa dialético-crítica (Escola de Frankfurt).

Ambos os métodos (quantidade e qualidade) não são incompatíveis e não se contradizem; estão imbricados. 
Papel pesq.

Principais

Princípios de complexidade,

critérios pesq.

consistência, unidade dos

contrários e triangulação.

Artigo recebido em 06/06/2008 - Aprovado em 16/06/2008 